\title{
FUNDAMENTOS PARA LA CRÍTICA DEL DISEÑO GRÁFICO
}

\author{
Fundamentals for graphic design criticism
}

José de Jesús Flores-Figueroa ${ }^{1}$

Fecha de recepción: 20 de septiembre de 2019.

Fecha de aceptación: 6 de enero de 2020

1- Nacionalidad: Mexicana. Grado: Doctor en Letras Modernas. Adscripción: Universidad Autónoma de Ciudad Juárez. Correo electrónico: jose.flores@uacj.mx. (iD ORCID: http://orcid.org/0000-0001-6266-5946 


\section{Resumen}

El diseño gráfico carece de una crítica, tal y como la tienen otras disciplinas. Usualmente se reduce a describir la obra sin explicar las articulaciones de los productos con la sociedad. Se propone un modelo de crítica basado en seis etapas: 1 . Etapa del juicio funcional: Señala si el proyecto cumple el objetivo de comunicar. 2. Etapa de la descripción formal: sobre seis variables, a saber: 1 composición, 2 ilustración, 3 figuras geométricas, 4 tipografía, 5 color y 6 fotografía. 3. Etapa de la descripción conceptual: Revisar y valorar tres variables: estética, innovación y abstracción. 4. Etapa del análisis de las relaciones producto-sociedad y cómo se articulan entre sí. Depende de la cosmovisión del crítico. 5. Proceso de redacción 6. Proceso de difusión. De concretarse una crítica del diseño, se dará otro paso en la conformación del diseñólogo, quién será el intelectual orgánico del diseño. Esta propuesta cubre una necesidad, dado que no existe una crítica del diseño gráfico como tal. Asimismo, enriquece la capacidad de exégesis del diseñador, además de que abrirá nuevas líneas de investigación en la crítica del diseño.

Palabras clave: Crítica, Diseño gráfico, Cosmovisión, Diseñólogo, Intelectual orgánico, Estudios culturales.

\section{Abstract}

Unlike other disciplines, Graphic Design lacks criticism, which is reduced only to the description of the work, without an explanation of the relationships between the products and society. A critique model built is proposed in six stages: 1. Stage of functional judgment: indicates if the project accomplishes the objective of communication. 2. Stage of formal description: based on six variables: composition, illustration, geometric shapes, typography, color, and photography. 3. Stage of conceptual description: revision and valorization of three variables: aesthetics, innovation, and abstraction. 4. Stage of analysis of the relations between the product and society, and connections between each other. Determined by the mental structures from the critic. 5. Redaction process. 6. Diffusion process. If Graphic Design criticism is finalized, we may take another step in the creation of the Designer-scholar, who could take the position of an organic intellectual in the disciplines of Design. This proposal covers a need since there is no criticism of Graphic Design as such. It also enriches the designer's exegesis capacity, in addition to opening new lines of research in Design criticism.

Keywords: Criticism, Graphic design, Worldview, Designer-scholar, Organic intellectual, Cultural studies. 


\section{Introducción}

$\mathrm{E}$ n términos tanto temporales como espaciales, en Occidente la crítica de obras se puede rastrear desde la Grecia Antigua, en épocas tan remotas como las de Aristóteles y Platón. En la Poética, Aristóteles ya planteaba una forma para escribir y apreciar un texto o representación teatral de acuerdo con patrones establecidos con base en la experiencia, la estética y el juicio del propio filósofo.

Además, a lo largo de la historia humana, casi siempre la crítica corre paralela al surgimiento de cualquier objeto humano que se presente como creativo o innovador. Ante un producto las personas siempre tienen diferentes perspectivas y opiniones en cuanto a la calidad o tratamiento con el que se llevó a cabo el proyecto. Sin embargo, en el panorama de la crítica formal, emitir una opinión basada solamente en el sentido común no tiene relevancia ni trascendencia, excepto, tal vez para quien la emite. Al mismo tiempo, la crítica no debería quedarse en una descripción detallada del objeto resaltando sus principales características y comparándolas con otro objeto similar.

La crítica es, probablemente, el modo de pensamiento más característico de la modernidad. Su particularidad y especificidad respecto a modos discursivos anteriores radica en que conecta de un modo inextricable la producción de los artefactos culturales -literarios o artísticos- con el campo de los saberes y con el debate público. Se podría decir que lo que hoy reconocemos como $\neg$ «ámbito de la cultura» surge en gran medida como consecuencia de la trama de análisis, juicios y posicionamientos desarrollados por la crítica y diseminados en debates, revistas, libros y otros medios de comunicación (Guasch y Carrillo, 2003: 13).

Cierto, la crítica es indispensable no sólo para hacer más comprensible cualquier obra creativa, sino para explicar su relación con el mundo, con las sociedades, con las maneras en que interactúan las personas y para generar herramientas que mejoren la vida de las sociedades humanas en general. Asimismo, es factible afirmar que, en la segunda década del siglo XXI, existen diversos tipos de crítica, casi tantos como los productos creativos que se dan en el mundo. Así, se pueden enumerar: la crítica de cine, de literatura, de modas, de pintura, de escultura, de teatro, de música comercial, de música clásica, entre otros. Es decir, que cada creación conlleva su escrupuloso análisis propio, elaborado por terceros y dirigido a creadores pares, pero especialmente al espectador que se inclina al goce de esas expresiones creativas concretas. Este tipo de análisis, planteado como crítica, ha derivado en múltiples corrientes y cada una de ellas plantea su propia metodología en concordancia con las aportaciones que pretende destacar y su percepción de valores en su propia escala. Incluso, se puede decir que cada crítico tiene sus formas para ejercer y delimitar a la crítica, cosa que finalmente define el carácter de esta actividad siempre compuesta, se quiera o no, por juicios de valor. Como se señaló líneas arriba, la actividad de la crítica se ha desarrollado por milenios en ciertas disciplinas, pero en otros casos la crítica, 
junto con su objeto de estudio, son recientes, como el caso del cine o incluso apenas empieza a esbozarse, como en el caso de la música comercial. En lo que respecta a la crítica del diseño gráfico, parece que sus tentativas son precisamente eso, sólo tentativas. No importa si el origen del diseño gráfico se considera en el nacimiento de la cultura o con la invención de la escritura, en el Renacimiento o incluso en la Revolución Industrial, la crítica parece abandonar e incluso ignorar reiteradamente a esta práctica creativa.

Esta situación de la aparente ausencia de la crítica formal del diseño gráfico contradice lo dicho en el sentido de que cada propuesta creativa genera su propia crítica formal y aunque es un tema interesante para aclarar, por el momento no forma parte de esta investigación. Sin embargo, esta disyuntiva indefectiblemente conduce a la reflexión, a abordar, por lo menos brevemente el estado de la cuestión acerca de los trabajos más sólidos encontrados en esta área en los tiempos más recientes.

\section{Estado del arte}

El primero de los casos que se debe mencionar viene de los Estados Unidos. Desde 1994 y hasta 2005, se editaron, hasta donde se pudo investigar, cinco tomos de crítica del diseño titulados Looking closer. Critical writing on graphic design. El proyecto, encabezado por Michael Bierut como editor, plantea el tema de una manera clara y sistemática. Asimismo, los artículos incluidos son muestra de una lúcida ilación de ideas, con una redacción acorde a la difusión de los contenidos para un lector que va desde un espectador interesado en el tema o un incipiente diseñador hasta un avezado investigador en el campo. Los cinco volúmenes abarcan prácticamente todas las cuestiones relacionadas con el hacer del diseño gráfico. Como ejemplo, se pueden citar títulos como: Natural history of the typography, Cult of the ugly, Who needs ethics, Terminal technology, Visual pop, Good designs is good business, por enunciar algunos.

Una de las virtudes de estas ediciones, son las reflexiones que se hacen en las introducciones de cada una de ellas. De hecho, son textos que bien pueden ser usados en términos didácticos para los estudiantes e investigadores interesados en el tema de la crítica del diseño gráfico. Al mismo tiempo, en el contenido en general de los libros, no sólo aparece una serie de aportaciones de varios críticos, sino que se puede deducir una manera clara de transmitir las ideas sin que el lector sea por fuerza un diseñador. Del mismo modo, en cada uno de los prefacios se aborda el tema de la crítica. Así, por ejemplo, en el primer libro de la colección, Heller se refiere al estado de dicho quehacer:

Aunque la calidad del diseño escrito se ha incrementado, para reemplazar al elogio por compañerismo, los redactores contemporáneos están entrampados con el problema básico de cómo desarrollar un vocabulario crítico; algunos pocos están adoptando modelos existentes como el de la semiótica y la teoría lingüística francesa, algunos otros están siguiendo formas menos académicas (Heller, 1994: xiv). 
Sin embargo, cabe mencionar que puede ser cierto que apenas se esboza un vocabulario ${ }^{2}$ propio para la crítica de esta disciplina gráfica, pero lo que parece todavía más apremiante es que la incipiente crítica parece quedarse, en la inmensa mayoría de los casos, en una simple relatoría de hechos presentados en la obra y precisamente esta es la debilidad de los libros de Looking closer. Critical writing on graphic design, su poca profundidad en, precisamente, la crítica. No parece buscar una explicación o descripción de las maneras en que el diseño se relaciona con su entorno, tampoco aparecen las influencias negativas o positivas en la sociedad a consecuencia del manejo de los mensajes en las obras de diseño. De alguna manera, los múltiples intentos se quedan en fluidas descripciones de obras o hechos históricos ubicados en tiempo y espacio. En la mayoría de los textos no se encuentra una posición más allá de lo descriptivo, de lo narrativo histórico o del tratamiento estético de las obras diseñísticas. Es decir, no se plantea un análisis sociocultural de las obras y por ende de las relaciones del diseño con la sociedad ni de manera individual de cada pieza ni globalmente como actividad sustantiva, en la vida cotidiana de nuestra era. De tal manera, no se dan análisis en la repetición de estereotipos que promueven ciertas actitudes negativas o positivas en la sociedad. Así como tampoco aparecen juicios severos en cuanto a la forma en que los diseñadores conceptualizan y articulan su trabajo con los promotores del diseño, los proveedores, los colegas y con la sociedad en general.

Otro autor que toca el tema de la crítica del diseño es Juan Acha en su libro Crítica del arte. Teoría y práctica. El título es ilustrador del tema. Esta obra aporta varios elementos altamente enriquecedores en la búsqueda que se emprende por la conformación de una metodología de la crítica del diseño gráfico. El primero que se puede señalar es que su exposición muestra paso a paso las variables que se toman en cuenta en su propuesta para generar una sólida crítica del arte. En segundo lugar, expone clara y detalladamente el porqué de la selección de dichas variables. Asimismo, analiza profusamente la manera en que se entrelazan las nociones destacadas de la obra y que se seleccionan para su estudio. También plantea que sumados todos estos factores dan por resultado un modelo de análisis de obras plásticas. Finalmente, afirma que este proceso, explicado punto por punto, se puede extrapolar al diseño gráfico usando los mismos valores que se evalúan en la plástica, aseveración que podría tomarse como cierta, si concordamos con su visión.

Empero, se pueden argumentar dos claras inconsistencias: Primero, el alcance que tiene su propuesta es incompleto, al igual que los libros de Looking closer. Critical writing on graphic design, pues se queda únicamente en la valoración de la obra sin relacionarla con su entorno social. Es decir, con base en la metodología que propone, queda poco espacio para reflexiones de lo que la obra provoca en el espectador individual, más allá de la contemplación estética o cultural y mucho menos visualiza la influencia de las obras en la sociedad como conjunto. En segundo lugar, está la imposibilidad absoluta de extrapolar al diseño gráfico su modelo de la manera en que lo presenta. Esta afirmación se da puesto que, como muchos expertos señalan, la inmensa mayoría del arte plástico no nace por encargo, más bien se deriva de una iniciativa del propio creador, mientras que el diseño gráfico surge, en la mayoría de los casos, por mandato de un promotor. Este simple hecho, invalida la propuesta de Acha de aplicar la crítica del arte (pictórico) al diseño. En consecuencia, se puede afirmar que los valores a considerarse para la crítica de

2- No es posible olvidar que incluso en la segunda década del siglo XXI, la inmensa mayoría de los términos con los que trabaja el diseño gráfico han sido extrapolados desde las artes visuales como es el caso de la pintura y la escultura. 
obras diseñísticas deben partir de elementos propios, que son diametralmente distintos a los artísticos. Una prueba de esto último son las propias palabras del autor cuando, casi al final de su libro ejemplifica la aplicación del modelo que propone:

Se sorprenderán al ver aquí el ejemplo de una portada de libro, producto del diseño gráfico, sin haber recibido ustedes conocimientos al respecto en estas páginas. Sin embargo, esto no constituye un capricho ni es improcedente hacerlo: les bastará a ustedes aplicar el enfoque crítico requerido por todas las obras de arte (...) (Acha, 1992:163).

En la obra del autor, el resto del texto explicativo que aborda la crítica del diseño gráfico no abarca dos cuartillas completas en un libro con un total de 222 páginas. Entonces, básicamente es posible deducir que dada la brevedad que le da a la crítica del diseño, lo asume como una actividad menor o en todo caso como minúscula, cuando en realidad el diseño gráfico es un proceso comunicacional que tiene poco que ver con el arte plástico, por lo que amerita una metodología propia basada en las razones de su existencia, usos, objetivos y la manera en cómo se relaciona con la sociedad, por todo esto, es de considerar que su perspectiva no es totalmente correcta. Otro autor que toca el punto de la crítica es Norberto Chaves. En su libro El oficio de diseñar. Propuesta a la conciencia crítica de los que comienzan, él aborda cuestiones del entorno del diseño gráfico de una manera puntual y profunda. Asimismo, es extraordinariamente incisivo en los temas que toca no sólo en cómo se involucra el profesional del diseño con su propia profesión sino también en la manera en que se articulan dichas ilaciones con la sociedad en su conjunto.

Este autor, probablemente es el que plantea una mejor perspectiva en cuanto a la crítica del diseño gráfico. Toca temas como las relaciones entre el diseño y el medio ambiente, las manifestaciones culturales, la propia definición del diseño, las relaciones con la tecnología, la ética, etcétera. Sus enfoques superan el análisis promedio de otros autores cuyo estándar raya en el trato al diseño como una herramienta absolutamente neutra donde las cosas se han hecho bien desde siempre, donde sus creaciones no provocan ni males ni bienes como resultado, estos autores parecen ubicar al diseño gráfico como algo absolutamente inocuo y totalmente neutral, esto entendido en la influencia que puede tener en las personas, pero por otro lado consideran al diseño como una herramienta panaséica y todopoderosa. Chaves promueve el rompimiento de los paradigmas académicos que se plantean niveles imaginarios de las acciones del diseño gráfico, donde se enlaza de manera idílica con el arte, con influencias ficticias en los promotores del diseño.

Por lo que toca a la parte negativa de su propuesta, falta el análisis inicial de obras, autores o corrientes diseñísticas, pues sobre este examen se puede iniciar la deducción de cómo se relacionan los productos del diseño con la sociedad. Otro defecto del que adolece esta proposición metodológica es la falta de metodización a partir de la cual se pueda conformar un cuerpo coherente de análisis. Es decir, en este libro en particular, los temas expuestos no guardan una coherencia en cuanto a su selección ni se ve un principio ni una meta que alcanzar. En otras palabras, no parece existir una línea continua de pensamiento con el fin de conformar un proceso metodológico a través del cual se hagan evaluaciones consistentes de los factores que afectan el sujeto de estudio. De igual manera, su discurso no tiende a crear una pedagogía a través de la cual los estudiantes, así como los recién egresados de las carreras de diseño entiendan y aprendan la mecánica de la crítica del diseño gráfico. 
Finalmente, si bien es cierto que la obra es un compendio de conferencias presentadas por el autor en un tiempo determinado, es factible pensar que no por eso se debe evitar una ilación con una imbricación de opiniones visibles y sistemáticas.

En un cuarto caso aparece el libro de La crítica del diseño de Flores y Balderrama. El mérito de esta obra es que define las variables básicas a partir de las cuales se puede enjuiciar un proyecto diseñístico. Estos autores afirman que el diseño gráfico, al ser un proceso comunicacional, se debe juzgar sobre esta base y por las características que comparte todo proyecto de diseño, es decir la estética, la innovación y la abstracción. Asimismo, proponen una tipología para cada una de estas características del diseño con las que sugieren se puede evaluar con mayor precisión un trabajo diseñístico, en lo académico y en lo profesional, con el fin de minimizar los juicios subjetivos en un nivel de imprecisión excesivo tales como "es un buen diseño", "es un mal diseño".

Su desventaja más obvia es que no proponen ni ejemplifican un paradigma completo para hacer crítica. Asimismo, dejan de lado la descripción de las obras sin delimitar la mecánica para elegir los elementos que deben, así como el porqué, destacarse para su juicio. Tampoco buscan desentrañar las relaciones entre la producción del diseño y la sociedad, ni mucho menos cómo se generan estas ni cómo se influyen mutuamente. Estos factores dan como resultado una propuesta inconclusa, que no genera un modelo de análisis encaminado a desarrollar la crítica del diseño gráfico.

\section{Marco teórico}

Como se afirma con anterioridad, plantear una crítica que sólo sea descriptiva de las obras del diseño gráfico no tiene una trascendencia acorde a la difusión que tienen sus proyectos, de ser así, simplemente sería un ejercicio casi lúdico. La crítica, al igual que el diseño gráfico, debe evolucionar en todos los sentidos posibles, primero mirándose internamente y después observando a la sociedad. Es decir, deben criticarse primero a sí mismos y hasta hoy no se han sometido a este ejercicio al menos no como actividad diseñística, cosa que sí han hecho otras disciplinas creativas e innovadoras como el caso de la publicidad y la mercadotecnia. Esta omisión se da a pesar de la presencia tan profusa de esta actividad en el mundo contemporáneo. En el panorama general cotidiano, hay otras industrias que parecen más obvias, como la música, el cine o los videojuegos, el diseño parece mimetizado en su propia masividad, pues independientemente de estar presente en prácticamente todos los horizontes de la vida moderna (desde la educación, la cultura, la publicidad, los medios de comunicación, la Internet, los videojuegos, la señalización de las ciudades, en los interiores de las edificaciones), contemplarlo como un simple elemento decorativo o invasor visual solamente describiendo sus componentes, no aportará gran cosa a su entendimiento como fenómeno social capaz de modificar o perpetuar comportamientos en las personas. De igual manera, perder de vista su potencial comunicativo, no exime de la exégesis a la que todo diseñador debería estar obligado, no sólo para entender los alcances tanto positivos como negativos de sus herramientas de trabajo, sino para entender el lugar que ocupa en una sociedad tan compleja como la que se vive en el siglo XXI. Sobre esta base, en líneas posteriores 
se propone un modelo de crítica para que se convierta en un proceso de juicio de sus productos, sus relaciones intrínsecas y excéntricas y cómo se articulan con la sociedad. En consecuencia, para llevar a cabo la propuesta de los fundamentos para la crítica del diseño, parece indispensable explorar inicialmente el concepto de crítica sobre el que se desarrollará la presente reflexión. De acuerdo con Eagleton (1999: 140) "La crítica moderna nació de una lucha contra el Estado absolutista; a menos que su futuro se defina ahora como una lucha contra el Estado burgués, pudiera no tener el más mínimo futuro". Esta aseveración tiene mucho que ver con el planteamiento hecho acerca de lo que debería ser la crítica del diseño gráfico, es decir que la crítica tiene, por fuerza, que contribuir al diálogo de ideas afines y contrarias para construir el conocimiento y reducir las diferencias sociales, políticas, culturales y económicas de nuestro mundo actual.

Entonces, si se acepta como cierto el dicho de Eagleton, tendremos que preguntarnos de inmediato: en un sentido general, ¿para qué sirve la crítica, cuál es su función? En primera instancia la crítica sirve para profundizar en la obra cualquiera que sea su naturaleza. No importa si es literaria, cinematográfica, musical o similar. Es decir, la crítica tiende a explicar y clarificar una obra. “(...) la crítica no es un apéndice superficial (...) sino su doble necesario (el texto nunca puede decir toda su verdad) (...)" (Todorov, 2005: 9). Pero, por el momento baste esta propuesta como paso inicial para definir la crítica del diseño gráfico, a pesar de que no cumple los requisitos que tanto se han anunciado líneas arriba en cuanto a una metodología, para realizar un análisis de proyectos de diseño. Por otro lado, Eagleton dice que:

La función del crítico contemporáneo es oponerse a ese dominio [de la clase hegemónica] volviendo a conectar lo simbólico con lo político, comprometiéndose a través del discurso y de la práctica con el proceso mediante el cual las necesidades, intereses y deseos reprimidos puedan asumir formas culturales que podrían unificarlos en una fuerza política colectiva. La del crítico contemporáneo es, pues una función tradicional (1999: 139).

Si bien ambas posiciones parecen absolutamente contradictorias, en realidad son dos partes de un mismo proceso al que pretende llegar esta propuesta. En primer lugar, hacer más legible la obra en su profundidad y en segundo lugar enunciar las posibles influencias, tanto positivas, como negativas que el proyecto tenga sobre la sociedad. En otras palabras, Todorov señala los primeros pasos en el proceso de la crítica, mientras que Eagleton apunta los finales. Al seguir explorando referencias de otros autores aparece Gómez que afirma:

...[la] «Crítica», no se olvide, implica, desde su raíz etimológica griega, la capacidad de juzgar, de analizar, de interpretar...y es potencialmente enjuiciadora de valores implícitos en la obra. Por eso, tiene que existir una «actividad crítica», limitada a la tarea del escrutinio para la que ha sido pensada, humilde en sus objetivos, sin más pretensiones que la de desvelar algunas de las múltiples facetas de significación que intervienen en la conformación de una determinada textualidad (1996: 15). 
Esta propuesta parece cubrir con más exactitud lo que debe ser una crítica en sus primeras fases, juzga, analiza, interpreta... como dice el autor. En concreto, el término que se debe resaltar es el de "valores implícitos en la obra", pues no es aceptable que deba referirse solamente a lo creativo, sino que debe cubrir también lo social, pero señalado como prioridad en las relaciones culturales entre diferentes actores sociales y cómo se integran a través del diseño. Sin embargo, en términos conceptuales y no operativos, una noción que parece mucho más precisa y adecuada a la presente reflexión la da Ryan:

La crítica es el análisis de la vida cultural humana. Lo que la ciencia hace con la vida física, la crítica lo hace con la vida cultural. La define, estudia e intenta explicar cómo funciona y la manera en que lo hace (2012: posición 173).

En concreto, para avanzar en la propuesta, no es descabellado que la crítica del diseño gráfico analiza, describe e interpreta los elementos de un diseño, la obra de un autor o de una corriente, para luego reconocer cómo se articulan dichos proyectos diseñísticos con la sociedad e intenta explicar las relaciones entre contradicciones y fuerzas sociales implicadas en todo momento y que siempre se reflejan, consciente o inconscientemente, en el trabajo del diseñador.

Sobre este enunciado se puede revisar el modelo de crítica del diseño gráfico que se propone.

\section{Propuesta metodológica}

El modelo de crítica planteado se divide en seis etapas.

\subsection{Etapa de juicio funcional}

En esta parte del proceso se debe responder la pregunta obvia de ¿El proyecto analizado cumple con la función básica de un diseño? El punto de vista más coherente señala que el objetivo primordial del diseño gráfico es comunicar.

Otorgar otro objetivo más allá del comunicacional a una obra diseñística desvirtúa la naturaleza misma del proyecto. Se puede discutir, por ejemplo, que una ilustración puede rebasar esa meta y entonces destacarse por su estética, sin embargo, este resultado no sólo puede hacer inoperante el proceso de diseño, sino que podría colocarlo en el nivel del arte, por lo que entonces se le debería juzgar bajo una perspectiva diferente y con una metodología adecuada a su carácter. Frascara (2000) dice en su libro Diseño gráfico y comunicación:

(...) el diseño gráfico, visto como actividad, es la acción de concebir, programar, proyectar y realizar comunicaciones visuales...El diseñador gráfico trabaja en la interpretación, el ordenamiento y la presentación visual de mensajes...el diseñador gráfico es un especialista en comunicación humana, si bien su medio específico es el visual (...) el aspecto más esencial de la profesión, que no es el de crear formas, sino el de crear comunicaciones (19-21). 
Indudablemente Frascara visualiza al diseño gráfico como una herramienta comunicacional. Por lo que toca a Acha, este autor define así a los productos de esta actividad: "Se trata de espacios gráficos que deben informar por medio de la atracción y el convencimiento (...)” (1990: 102).

Del mismo modo Ambrose y Aono-Billson afirman de manera tajante: "El papel del diseñador es, en última instancia, la de comunicador, bien sea como autor, protagonista o mero proveedor de soluciones de comunicación." (2011: 26)

En lo que respecta a la presente reflexión, concuerda con el hecho de que el diseño gráfico es un proceso de comunicación y no tiene nada para compartir con el concepto tradicional de arte, por lo que para el juicio funcional del diseño se debe hacer sobre sus aciertos comunicacionales ${ }^{3}$. Por lo que el crítico debe responder siempre, en primera instancia, la pregunta de: ¿la sumatoria de los elementos técnicos logran en su conjunto comunicar el mensaje fundamental? En otras palabras, antes que nada, se debe evaluar si los elementos gráficos contribuyen a hacer más claro y eficiente el mensaje que genera todo el proceso del proyecto. Dichos elementos jamás deberían suplantar o mimetizar al comunicado. Si la meta no se alcanza, entonces el diseño se debe desestimar a pesar de que el resto de sus atributos puedan ser altamente destacables.

\subsection{Etapa de la descripción formal}

Una vez evaluado el valor comunicacional del diseño, se procede a la descripción formal de la obra partiendo de la base de los seis elementos técnicos que pueden ser utilizados en cualquier proyecto de diseño gráfico, a saber:

1 composición, 2 ilustración, 3 figuras geométricas, 4 tipografía, 5 color y 6 fotografía.

El análisis de la composición implica exponer, con la mayor claridad posible, la disposición de los elementos que aparecen en el proyecto. Mencionar si en el trabajo hay una sección aurea, si están dispuestos en cuadrícula, en tercios, en espiral, si se privilegia la perspectiva, si es dinámica, estática, etcétera.

El concepto de ilustración va desde la representación de un objeto con una o dos líneas hasta una expresión altamente detallada de cualquier objeto, sin importar si es a todo color o sólo en negro. Sin embargo, la única característica que no puede ser omitida es que la imagen no sea fotográfica, es decir, tiene que ser dibujada, sin importar si fue a mano o por medio de mecanismos digitales.

Las figuras geométricas, son obviamente círculos, cuadrados y triángulos, ya sean en solitario o en cualquier combinación compleja que derive en otras figuras.

La tipografía señala a las fuentes usadas para transmitir o reforzar un mensaje, sin importar si son letras formales o de fantasía, generadas a través de programas informáticos o dibujadas por el creador.

El color implica las tonalidades o ausencia de estas. Es decir, puede ser un solo color o cientos con sus correspondientes degradaciones, combinaciones tonales análogas, complementarias, primarias, secundarias, de contraste, cálidas, frías, etcétera.

3- El hecho de que para otros investigadores el diseño tenga otras funciones más importantes que la comunicación, no implica que se descalifique la propuesta de modelo que se propone. 
Finalmente, la fotografía que implica la captura de imágenes a través de un medio mecánico ya sea químico o digital.

No es necesario decir, que no siempre se encuentran todos estos elementos en una creación diseñística. Es factible que encontremos un proyecto de diseño conformado sólo por un texto hecho a mano o marcado en color negro omitiendo el resto de los que aquí se definen como elementos técnicos.

\subsection{Etapa de la descripción conceptual}

En este nivel se enjuician tres elementos que indefectiblemente todo proyecto de diseño tiene: estética, innovación y abstracción ${ }^{4}$.

Acerca de la estética, el crítico examinará el proyecto y definirá en qué categoría se puede ubicar el diseño en función de sus elementos más obvios. Así se puede clasificar una obra diseñística como bonita, sublime, kitsch, vogue, grotesca, tecno, cómica, humorística, o cualquiera de las categorías en las que se puedan definir elementos específicos y diferenciales en el terreno de la sensibilidad del receptor del diseño (Flores y Balderrama, 2014: 36-46).

En cuanto a los elementos de innovación, se juzgan los componentes estereotípicos, así como la manera en que el diseñador los reconfiguró.

La creatividad del diseñador está en el entendimiento de los estereotipos y en su capacidad para reconstruirlos...Un estereotipo debe cumplir cuatro funciones: $1 \mathrm{emi}-$ sor y receptor conocen su significado, 2 repetición suficiente de este, 3 estar ligado a un contexto específico, 4 su forma puede variar, pero mientras sea reconocido sigue considerándose estereotipo. (Flores y Alvarado, 2018: 5).

Desde esta perspectiva, al diseño no se le puede contemplar como un proceso creativo sino innovador, entendiendo al primero como un trabajo con resultados que no se han visto jamás. Un ejemplo son las obras de arte que rompen los paradigmas establecidos y abren nuevas rutas en la exploración de la inspiración humana en cualquier expresión artística. Por el contrario, lo innovador es aquello que ya existe, pero se presenta transformado y agradable para el espectador. Para esta propuesta se aceptan como adecuadas las categorías innovadoras de vanguardista, adaptada, reciclada y diluidora (Flores y Balderrama 2014: 57-70).

Finalmente está la abstracción. Dado que, como se dijo, usualmente el diseño es la plataforma de un mensaje emitido por un tercero, los elementos del diseño para codificar dicho comunicado deben ser lo más breves posibles puesto que un diseño usualmente es un comunicado no solicitado por el usuario, por lo que difícilmente le prestará más atención de la imprescindible para evaluar si es o no de su interés. Los niveles que de abstracción consideramos son: alto, medio y bajo. (Flores y Balderrama, 2014: 47-55).

4- Estos puntos se desarrollan con mucha más profundidad en el libro de Flores y Balderrama La crítica del diseño. 


\subsection{Etapa del análisis de las relaciones producto-sociedad y cómo se articulan entre sí}

Como reiteración, hacer una crítica simplemente descriptiva y valorativa de los elementos básicos del área de la obra, sin un juicio sobre la influencia positiva o negativa que ejerce en su entorno social, es un ejercicio del todo incompleto, por lo que se asume que en la crítica esta etapa debe ser la más importante, pues la acción de la crítica del diseño gráfico siempre debería tener un abordaje social. Pero ¿desde qué perspectiva cultural se debería hacer la crítica?

Esta respuesta la tiene que dar el propio diseñólogo, en función de su cosmovisión y sus ideas sobre la cultura. Para dar un ejemplo de los campos desde donde se puede hacer crítica del diseño con visión cultural, aparecen algunas de las propuestas según lo contempla Ryan: Formalismo, estructuralismo, crítica histórica, sicoanálisis y sicología, marxismo y crítica política, posestructuralismo, deconstrucción, estudios de género, étnicos, postcolonialistas, crítica transnacional, estudios culturales, etcétera (2012: 1-160). Del mismo modo, hay autores clásicos que pueden consultarse para sustentar una crítica sobre cualquiera de las visiones antes anotadas. Es importante señalar que, en esta etapa, el análisis tiene que estar basado en sólidas proposiciones ya sea que se acuda a reconocidos autores en el área, a manera de marco teórico, o si se proponen nuevos paradigmas, se soporten sobre profundas reflexiones y elementos empíricos que puedan ser probados, aprobados o refutados por pares. Por eso, cada uno de estos enfoques tiene una serie de fundamentos desde los cuales parten sus juicios e interpretación de la realidad. En cada caso, los investigadores que trabajan esas áreas han generado paradigmas teóricos para explicar los objetos de estudios en función de su percepción de la realidad. Así, por ejemplo, de acuerdo con Ryan (2014), los formalistas profundizan conceptos alrededor de cómo suceden las cosas, en la "forma" en que se dan. Forma, contenido, técnica, historia, narración y narrativa, punto de vista, motif, función, discurso, género, hipotaxis y parataxis, métrica poética y nueva crítica (3-5). Otro caso para ilustrar, también de Ryan, son los estudios de género, en los que se asumen conceptos como feminismo, heterosexualidad, patriarcado, identidad de género, diferencias, feminismo francés, homosocial, homosexualidad, etcétera (89-91).

\subsection{Proceso de redacción}

Un proceso de análisis, por muy riguroso que sea, no tiene sentido si no se plasma en un texto coherente encaminado a ser expuesto ante los pares para su discusión, evaluación, decantación, modificación y finalmente aceptación o rechazo. En consecuencia, se debe generar una redacción precisa, con argumentos sólidos y teóricos en cada una de las etapas de la crítica encaminada a ser publicada en un medio especializado, con el fin de fortalecer el trabajo, tanto teórico como práctico, de los diseñadores. 


\subsection{Proceso de difusión}

Una vez completado el proceso, la crítica debe ser publicada, puesta al alcance de los pares y diseñadores para aportar en el conocimiento del quehacer del diseño gráfico y al mismo tiempo someter las opiniones y resultados vertidos, para que sean discutidos en los foros correspondientes.

Esta propuesta se inclina por desarrollar una crítica del diseño a partir de los estudios culturales, dado que ambos conceptos ya se han vinculado en el pasado, pues según las palabras de Julier: "Para entablar la discusión sobre el consumo del diseño, los historiadores han partido de diversos discursos teóricos, desarrollados en los ámbitos de los estudios culturales, la antropología social, la sociología y la geografía cultural" (2010: 81). De tal manera que se hace necesario contextualizar esta perspectiva. Los estudios culturales nacen en Inglaterra después de la Segunda Guerra Mundial. En el tiempo que iniciaba la reconstrucción de esa nación, un grupo de académicos, al mirar los efectos del conflicto en su país, decidieron revisar exhaustivamente el estado de Inglaterra desde la perspectiva social, histórica, cultural, política y económica, desde el principio esto hizo a los estudios culturales, una propuesta interdisciplinaria.

La etapa de cristalización que representa el reconocimiento institucional de los estudios culturales durante la década de 1960 sería ininteligible si no se tuviese en cuenta un trabajo de maduración que se inicia unos diez años antes y que puede simbolizarse mediante las figuras de los tres padres fundadores que, de hecho, a semejanza de los mosqueteros de Dumas, son cuatro (Mattelart y Neveu, 2004: 36).

"Los estudios culturales surgieron como campo interdisciplinario en el mundo angloparlante en los años cincuenta y sesenta, como parte de un movimiento democratizador" (Szumurk e Irwin, 2013: 11). Formalmente, el término de "estudios culturales" se concreta en los años sesenta del siglo XX cuando Richard Hoggart funda el Centro de Estudios Culturales Contemporáneos (CCCS Centre for Contemporary Cultural Studies) en la Universidad de Birmingham. De hecho, a Hoggart se le considera uno de los padres fundadores de los estudios culturales junto con Raymond Williams, Edward P. Thompson y Stuart Hall. Los estudios culturales exploran las formas de producción de los objetos culturales y tratan de explicar la forma en que se articulan estas relaciones en la sociedad actual, de tal manera que este tipo de razonamientos revisa los discursos hegemónicos y contestatarios para encontrar el significado de cada uno en relación con el otro. Asimismo, pretenden desentrañar las consecuentes prácticas simbólicas que se generan o se perpetúan entre el poder y la subordinación. Como resultado, los estudios culturales basan su análisis en la cultura, así como en la sociedad misma. Para lograr su fin, se apoyan en disciplinas como la economía, la comunicación ${ }^{5}$ (especialmente en el uso de los medios de comunicación masiva), la antropología, la política, la historia, etcétera. Asimismo, usan plataformas interpretativas de la realidad como la ideología, la etnia, las cuestiones de género, etcétera. (Szumurk e Irwin, 2013: 15)

5- Sparke señala: "Los medios de comunicación de masas -el cine, la televisión, las revistas, la publicidad y los mismos productos e imágenes fabricados en serie- desempeñaron un papel decisivo a la hora de transmitir un "modelo de vida" apropiables mediante el consumo" (2010: 137) 
El interés de estos análisis también obedece a su densidad teórica (...) Numerosos textos se fijan en la manera en que las autoridades sociales intervienen en las subculturas para estigmatizar los comportamientos y a sus autores (Mattelart y Neveu, 2004: 53).

Es decir, con una herramienta como los estudios culturales, la crítica del diseño gráfico se vuelve mucho más profunda y rica, además rebasa el hecho de una descripción de una obra de diseño para evaluar su valor estético, innovador o de abstracción. Entonces, se puede entrar de lleno en el análisis de las relaciones entre los diferentes grupos sociales que interactúan entre sí, para también deducir el peso positivo o negativo que tienen unos sobre otros. Así, del naciente diseñólogo, a través del crítico del diseño gráfico, nace el intelectual orgánico ${ }^{6}$ del diseño ${ }^{7}$.

(...) la única "función" a la que debería querer aspirar un intelectual crítico: [es] la de generar un universo discursivo, que se transforme en el horizonte de toda una época, más allá de los avatares y las contingencias inmediatas del "nombre del autor" que dibujó por primera vez esa línea horizontal (Jameson en Grüner, 2003: 25).

Por otro lado, los estudios culturales encontraron un terreno fértil para desarrollarse en América Latina, donde a partir de los años 50 del siglo XX las personas iniciaron una lenta, pero continua organización y oposición a los gobiernos totalitarios. Como primera respuesta a esos avances de la sociedad civil, los gobiernos desataron violentas represiones contra su población. Luego de estas manifestaciones en contra del poder hegemónico gubernamental, en algunos países se lograron avances sustanciales en democracia y derechos humanos, pero en otros se endurecieron los gobiernos y se crearon dictaduras como en Centro y Sudamérica. En contraste, paralelo a la lucha por mejores condiciones de vida y democracia, se inició un reconocimiento a la cultura popular en la región, cosa que contribuyó al fortalecimiento de la identidad de cada nación y un alejamiento paulatino de las influencias de Estados Unidos y de Europa.

La investigación latinoamericana sobre culturas populares contemporáneas también se ha institucionalizado durante los años ochenta, sin perder por ello su inventiva. Buena prueba de ello son las aportaciones del hispanocolombiano Jesús Martín Barbero sobre las «mediaciones» y el «placer popular» (1987). Néstor García Canclini, argentino afincado en México, trabaja sobre la «hibridación cultural», la desterritorialización y las «comunidades de consumidores», el brasileño Renato Ortiz sobre la «moderna tradición» y la mundialización de lo «internacional-popular», o el mexicano Jorge González sobre los «frentes de la cultura cotidiana»" (Mattelart y Neveu, 2004: 119).

6- Desde la perspectiva de Gramsci, se puede visualizar esta figura como el pensador de un segmento de la sociedad que da homogeneidad a las ideas, en función de la interpretación del mundo que tiene ese grupo de personas. En otras palabras, estructura las ideas en términos sociales, culturales, políticos y económicos encaminadas a generar una consciencia coherente con su realidad y la de su entorno.

7- En el asunto que nos ocupa, el intelectual orgánico tendría que resolver, primeramente, las dos perspectivas que distorsionan su verdadera naturaleza. En términos generales, las personas ajenas al ámbito del diseño gráfico tienden a subvalorarlo como algo simple, con un nivel muy bajo de complejidad, mientras que los involucrados en su conformación lo sobrevaloran dándole funciones y capacidades que no tiene. En consecuencia, el diseñólogo, a través de la crítica del diseño, podría definir primero el valor justo del diseño en la sociedad, así como el de sus aportaciones implícitas, pero no señaladas de cualquier proyecto de diseño que llegue a cualquier parte de la comunidad en la que se reciban los mensajes. 
Varios de los autores que trabajan los estudios culturales han explorado los medios de comunicación y sus diferentes expresiones, como las películas, la publicidad, los programas de televisión y las revistas que están cargadas con un alto grado de influencia norteamericana.

En el mapa de los flujos mundiales de importación y exportación de investigaciones sobre los procesos culturales, los países de Latinoamérica también ocupan un lugar aparte.

Los interrogantes sobre las culturas populares y las identidades culturales en Latinoamérica ofrecen una extensa memoria política. Consustanciales a las luchas de emancipación contra la hegemonía cultural de Europa, y luego de Estados Unidos, estos interrogantes han estado presentes en numerosos proyectos de reforma y revoluciones sociales que han salpicado las respectivas historias de las naciones que componen el subcontinente. (Mattelart y Neveu, 2004: 118).

\section{Aplicación del modelo propuesto}

Con estos antecedentes, parece posible hacer un ejercicio de crítica con base en el modelo de análisis propuesto. Se presenta como caso de análisis un proyecto del ilustrador Mario Ramírez Regalado, quien desarrolló un fondo de pantalla para uso personal (figura 1).

\section{Figura 1. Fondo de pantalla}

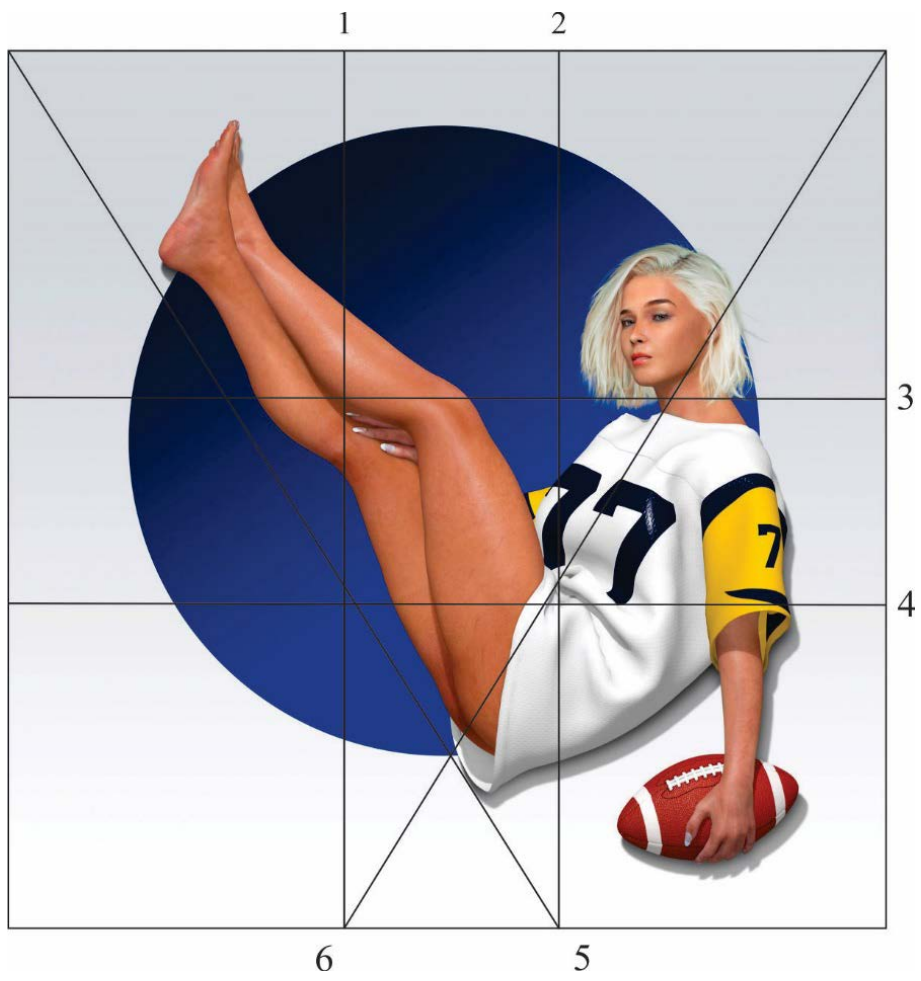

Figura 1. Todas las líneas rectas, incluyendo el marco se agregaron para explicar la composición, puesto que la ilustración inicial no tiene un contorno que la delimite. Autor: Mario Ramírez Regalado. 


\subsection{Etapa de juicio funcional}

$\mathrm{Al}$ ser un producto libre ${ }^{8}$, es posible afirmar que cumple con su objetivo comunicacional.

\subsection{Etapa de la descripción formal}

La composición del producto en cuestión está conformada en sección áurea. A dividirla en cuatro secciones por las líneas 1, 2, 3 y 4 obtenemos la división áurea básica. Así vemos que la cabeza (uno de los elementos más importantes en la figura humana) queda ubicada en el cuadrante superior de extrema derecha. Asimismo, al generar dos nuevas líneas áureas diagonales ( 5 y 6 ), encontramos que se forma una $\mathrm{V}$ que hace a la obra dinámica. Estás líneas imaginarias sostienen visualmente las piernas ilustradas de la mujer (de arriba abajo y de izquierda a derecha) y por el otro lado (de abajo a arriba y de izquierda a derecha) cruzan el torso de la figura femenina, empezando en las nalgas y cruzando justo por debajo de la oreja de la mujer creando otra línea imaginaria que soporta el torso. El diseño está compuesto sólo por elementos de ilustración. En cuanto a las figuras geométricas, se distingue un círculo que visualmente está por detrás de la figura femenina. Del mismo modo, aparece un cuadro implícito que contiene visualmente a todos los elementos que aparecen en el proyecto. En el cuadrante inferior derecho existe una figura geométrica ovoidal que representa el balón con que se juega el deporte conocido como fútbol americano. En lo que respecta a la tipografía, sólo aparece el número 77 en el jersey de la mujer. Los números son de tipo san serif. Dicho número aparece completo en el frente de la playera, pero sólo se distingue un 7 en la manga de la mencionada prenda. A pesar de la virtuosidad en la resolución de los detalles, se pueden contar pocos colores, a saber: El plano mayor del fondo que sostiene a todo el proyecto, está coloreado un tono azul grisáceo que se difumina de arriba abajo hasta un blanco completo. El color del círculo también se desvanece de arriba hacia abajo, pero en una diagonal en $45^{\circ}$ de izquierda a derecha, el tono parte de negro y termina en un azul obscuro. El jersey está irisado en tres tonos: blanco con mangas amarillas y vivos azules también en las mangas. Los números se representan en el mismo tono azul oscuro del vivo de las mangas. El resto de los tonos son de la piel de una persona caucásica, con el cabello blanco y los ojos verdes. El color del ovoide refleja los tonos reales de dichos objetos, es decir, café claro, con vivos en blanco y costuras negras. En la imagen no aparecen fotografías.

\subsection{Etapa de la descripción conceptual}

En términos de la tipología de la estética planteada por Flores y Balderrama (2014), la ilustración que se somete a juicio está dentro del parámetro de lo bonito. Es decir, es atractiva no sólo por la virtuosidad que se demuestra en la solución técnica de la ilustración, sino también por el hecho de que el objeto mis-

8- Los proyectos de diseño gráfico se pueden clasificar en dos: Los productos comprometidos que son solicitados específicamente por un promotor, bajo parámetros concretos y en donde el diseñador no tiene margen de influir en el contenido ni en el tipo de mensaje. Como ejemplos tenemos carteles, envases, identidades visuales, páginas web, etcétera. Por el otro lado están los productos libres en los que el diseñador tiene toda la libertad, tanto intencional como creativa, para generar el producto. Estos diseños sólo se pueden considerar en siete técnicas bien definidas: grafiti, cómic, memes, fanzine, fotografía, caricatura e ilustración. 
mo se ha diseñado en términos de los cánones de la belleza femenina occidental en los últimos cien años.

En lo que respecta a lo innovador, se puede decir que es prácticamente cero, dado que no aporta nada que no se haya visto antes. De tal manera que se puede insertar en la clasificación de reciclada, de acuerdo con los parámetros de Flores y Balderrama. Para soportar este juicio baste comparar las ilustraciones y fotografías que nacieron en los años 20 y 30 del siglo $\mathrm{XX}$ y que fueron bautizadas como pin-up. La representación que se analiza es fundamentalmente la misma de los pin-ups.

El nivel de abstracción que presenta el trabajo que analizamos claramente es bajo. Los detalles son definidos, con tendencia al hiperrealismo de la pintura y la ilustración, por lo que la abstracción prácticamente desaparece.

\subsection{Etapa del análisis de las relaciones producto-sociedad y cómo se articulan entre sí}

El proyecto que se analiza presenta algunos detalles que, desde el punto de vista de los estudios culturales, se pueden decodificar con relativa facilidad. El primero que revisaremos será el de la hegemonía de acuerdo con la perspectiva de Gramsci quien

(...) propuso una serie de herramientas conceptuales para entender las formas históricas concretas en que se ejerce la dominación por parte de ciertos grupos o clases sobre otros, y los mecanismos políticos y culturales que dan sustento a esas formas. Lo que buscaba Gramsci era analizar la dialéctica entre coerción y consenso dentro de ese proceso $y$, al mismo tiempo, superar las interpretaciones economicistas de la historia y la política al introducir de manera central el papel de la cultura dentro del análisis de la dominación (Szurmuk y Mckee, 2009: 125).

En primer lugar, la ilustración representa un deporte nacido en los Estados Unidos de América. Esta competencia no está tan arraigada en México como otras actividades deportivas profesionales y de aficionados, pues en cuanto a popularidad (ya sea como práctica o como espectáculo) están por encima la lucha libre y el fútbol soccer. Según comentario del autor, su afición a este deporte se debe a dos razones: la primera que lo practicó durante su época de estudiante de educación media superior, así, explica que el jersey representado evoca su uniforme de jugador aficionado y la segunda que sigue por televisión, los encuentros profesionales que se generan en los Estados Unidos. No sobra decir que dichos enfrentamientos deportivos son transmitidos semanalmente desde los Estados Unidos a México, con un rating adecuado para que represente ganancias para las estaciones que lo transmiten, también norteamericanas, o en su caso retransmisoras mexicanas que venden los espacios publicitarios.

En segundo lugar, aparece la figura femenina. La estilización con la que se representa denota una marcada inclinación al canon de belleza establecido por la cultura norteamericana. Piel blanca, cabello rubio platinado y largo, ojos color verde, joven, uñas largas y pintadas, maquillada, labios carmesíes. Asimismo, el estereotipo de la resolución gráfica, como ya se dijo, de una representación pin-up, una expresión nacida en Norteamérica. 
En ambos casos, se puede asumir que estas influencias norteamericanas, en la forma de presentarse en la realidad mexicana, tienen que ver con la hibridación pues cuando

(...) se piensa como un fenómeno indefectiblemente asociado a la modernidad, tal y como ésta se configura en la lógica del mercado productor de consumidores y rearticulador de identidades ciudadanas en la globalización y en las intersecciones entre la cultura de élite, la industria cultural y la cultura popular, así como el papel que el estado y los organismos privados juegan en los procesos generados por las reglas de producción simbólica de los bienes culturales (Szurmuk y Mckee, 2009: 134).

En tercer lugar, podemos hacer referencia a la decodificación sexual de la imagen en términos de la actitud, la pose y la ropa de la mujer. Se representa a una mujer joven, voluptuosa y atractiva. Su actitud es una mezcla de timidez y seducción. Sin embargo, la sexualización se decodifica no sólo por la postura y el porte, sino también porque la playera sólo cubre el torso y la pose muestra las piernas y la parte baja de las nalgas en una posición de venta sexual de la imagen.

Luego sólo restarían los procesos de redacción y difusión, que se puede deducir, están implícitos en este ejemplo que trabajamos.

\section{Conclusión}

La crítica corre paralela a cualquier objeto creativo o innovador. Pero, justo es preguntarse, ¿para qué sirve la crítica? Primero, para profundizar en la obra, pero especialmente para enunciar las posibles influencias tanto positivas como negativas que el proyecto creativo tenga sobre la sociedad. En consecuencia, la crítica del diseño gráfico tendría que contribuir al diálogo de ideas afines y contrarias para construir el conocimiento y reducir las diferencias sociales, políticas, culturales y económicas de nuestro mundo actual, pero en la actualidad este tipo de ejercicio prácticamente no existe. Esta omisión se da a pesar de la presencia de productos del diseño en prácticamente cualquier actividad y lugar de la sociedad.

Usualmente, al diseño gráfico se le contempla como un elemento decorativo o invasor visual. En lo que respecta a su crítica sólo parece haber tentativas que se detienen en una descripción de sus productos y de sus componentes, esto no aporta gran cosa a su entendimiento como fenómeno social capaz de modificar o perpetuar comportamientos en las personas. Emitir una opinión basada solamente en el sentido común para calificarlo o descalificarlo, no tiene relevancia ni trascendencia.

Aunque se han hecho algunos intentos para crear una crítica del diseño gráfico, parece que todos se han quedado a medias. Cierto que algunos sí plantean el tema de una manera clara, sistemática y lúcida, con una redacción acorde a la difusión de los contenidos para un lector interesado en el tema hasta un avezado investigador en el campo. Otros abarcan las cuestiones relacionadas con el hacer del diseño gráfico con buenos resultados en términos didácticos para los estudiantes e investigadores. Algunos de ellos incluso son extraordinariamente incisivos en los temas que tocan, pero, la incipiente crítica del diseño parece quedarse, en la inmensa mayoría de los casos, en una simple relatoría de hechos. No parece buscar una explicación o descripción de las maneras en que el diseño se relaciona con su entorno, 
tampoco aparecen juicios severos en cuanto a la forma en que los diseñadores conceptualizan y articulan su trabajo con los promotores del diseño, los proveedores, los colegas y con la sociedad en general. En resumen, algunos intentos sólo hacen la descripción del proyecto, otros pretenden ser más incisivos, pero no logran articular una secuencia entre descripción y las relaciones de los productos con la sociedad y finalmente definir si el proyecto es útil en términos de la comunicación a la que está obligado el proyecto. Este texto define a la crítica del diseño como: La crítica del diseño gráfico analiza, describe e interpreta los elementos de un diseño, la obra de un autor o de una corriente, para luego reconocer cómo se articulan dichos proyectos diseñísticos con la sociedad e intenta explicar las relaciones entre contradicciones y fuerzas sociales implicadas en todo momento y que siempre se reflejan, consciente o inconscientemente, en el trabajo del diseñador.

Asimismo, se propone un modelo de crítica dividido en seis etapas.

1. Etapa de juicio funcional: Señala si cumple el objetivo de comunicar del diseño gráfico.

2. Etapa de la descripción formal: Sobre seis variables, a saber: 1 composición, 2 ilustración, 3 figuras geométricas, 4 tipografía, 5 color y 6 fotografía.

3. Etapa de la descripción conceptual: Revisar y valorar tres variables: estética, innovación y abstracción.

4. Etapa del análisis de las relaciones producto-sociedad y cómo se articulan entre sí. Depende de la cosmovisión del crítico.

5. Proceso de redacción

6. Proceso de difusión

De concretarse una crítica del diseño, se dará otro paso en la conformación del diseñólogo, quién será el intelectual orgánico del diseño. Finalmente, como se dijo en el resumen: Esta propuesta cubre una necesidad dado que no existe una crítica del diseño gráfico como tal. Asimismo, enriquece la capacidad de exégesis del diseñador, además de que abrirá nuevas líneas de investigación en la crítica del diseño.

\section{Referencias}

Acha, Juan. 1992. Crítica del arte. Teoría y práctica. Ciudad de México: Trillas Editores. 1990. Introducción a la teoría de los diseños. Ciudad de México: Trillas Editores.

Ambrose, Gavin y Nigel Aono-Billson. 2011. Bases de diseño gráfico enfoque y lenguaje. Barcelona, España: AVA Publishing SA

Aristóteles. 1946. Obras completas de Aristóteles. Poética. Ciudad de México: Universidad Nacional Autónoma de México.

Bierut, Michael, William Drentel y Steven Heller. 1994. Looking closer. Critical writing on graphic design. Nueva York: Allworth Press.

Chaves, Norberto. 2001. El oficio de diseñar. Propuestas a la conciencia crítica de los que comienzan. Barcelona: Editorial Gustavo Gili. 
Eagleton, Terry. 1999. La función de la crítica. Barcelona: Paidos Studio.

Flores, José e Ivette Alvarado. 2018. Estereotipo y creatividad en el diseño. Taller Servicio 24 Horas, (27): 5-16 Flores, José y César Balderrama. 2014. La crítica del diseño. Ciudad de México: Trillas.

Frascara, Jorge. 2000. Diseño gráfico y comunicación. Buenos Aires: Ediciones Infinito. Gómez, Fernando. 1996. La crítica literaria del siglo XX. Madrid: Espasa Calpe.

Grüner, Eduardo. 2003. El retorno de la teoría crítica de la cultura: una introducción alegórica a Jameson y Žižek, Estudios culturales. Reflexiones sobre el multiculturalismo.

Buenos Aires: Paidos.

Guasch, Anna y Jesús Carrillo. 2003. La crítica del arte. Historia, teoría y praxis. Madrid: Ediciones del Serbal.

Heller, Steven. 1994. Looking closer. Critical writing on graphic design, Nueva York: Editorial Allworth Press.

Julier, Guy. 2010. La cultural del diseño. Barcelona: Gustavo Gili.

Mattelart, Armand y Érik Neveu. 2004. Introducción a los estudios culturales. Ciudad de México: Editorial Paidos Mexicana.

Ryan, Michael. 2012. An Introduction to Criticism: Literature - Film - Culture. West Sussex, United Kingdom: John Wiley \& Sons Ltd.

Sparke, Penny. 2010. Diseño y cultura una introducción. Desde 1900 hasta la actualidad. Barcelona: Gustavo Gili.

Szumurk, Mónica y Robert Irwin (Coordinadores). 2009. Diccionario de estudios culturales latinoamericanos. México: Grupo Editorial Siglo XXI.

Todorov, Tzvetan. 2005. La crítica de la crítica. Barcelona: Editorial Paidos Surcos II. 